\title{
The Authorisation Scheme for Biocidal Products in Switzerland
}

\author{
Dag Kappes and Brunhilde Kolp Buchs*
}

The Swiss Ordinance on Biocidal Products is technically equivalent to the Biocidal Products Regulation (BPR) of the EU. As a result, the requirements concerning the harmonised authorisation procedures and the lists of active substances in the EU and Switzerland are identical. Therefore, in 2015 both parties renewed the existing chapter on 'Biocidal Products' in the EUCH Mutual Recognition Agreement, which until 2013 had been based on the Biocidal Products Directive. Due to mutual recognition of authorisations of biocidal products, technical barriers to trade are avoided while maintaining the high level of protection. Furthermore, Switzerland participates in several BPR expert groups on EU level. This international exchange of knowledge and experience offers the opportunity to continuously improve the assessment techniques and to contribute to its harmonised development. Switzerland has to comply with the acquis. Consequently its room for manoeuvre concerning pragmatic solutions, eg for niche products, is therefore limited. The population benefits from the high level of protection. On the one hand, industry benefits from the same requirements and the possibility of mutual recognition of authorisations. On the other hand, small and medium enterprises operating only on the relatively small Swiss market suffer under the costs for the dossier preparation and the fees. Overall, the positive effects are likely to predominate due to the high level of protection.

\section{Introduction: Switzerland and the EU - The Bilateral Approach}

In 1992, the Swiss population voted against the membership in the European Economic Area (EEA). However, the strongly export-oriented Swiss economy needs access to the market of the European Union (EU). The Swiss Government, the Federal Council, therefore adopted on 30 June 1993 a decision which aimed at extensive regulatory harmonisation with the European Community (EC). Harmonisation reduced technical barriers to trade and at the same time, it allowed the conclusion of bilateral agreements with the EC in certain areas, including the legislation on chemicals and biocidal products. As a result, the Federal Council drafted a Chemicals Act (ChemA, SR 813.1) and referred it to Parliament. ${ }^{1}$ The Parliament adopted the ChemA in 2000. ${ }^{2}$ Based on the ChemA, the Federal Council has commissioned certain federal offices to draw up the relevant delegated acts (implementing provisions) including one for biocidal products. ${ }^{3}$ The new Chemicals Legislation including the Ordinance on Biocidal Products (OBP) entered into force on 1 August 2005. ${ }^{4}$

\section{The Harmonisation and the Agreement under the Biocidal Products Directive}

\section{The Swiss Ordinance on Biocidal Products 2005}

With respect to a possible bilateral EU-Switzerland agreement, the OBP needed to be designed to work

\section{DOI: $10.21552 / \mathrm{icrl} / 2019 / 2 / 5$}

* Brunhilde Kolp Buchs is Head of Section REACH and Risk Management of the Division of Chemical Products at the Swiss Federal Office of Public Health (FOPH). Dag Kappes is a Scientific Officer in the same section. For correspondence: $<$ dag .kappes@bag.admin.ch>.

1 For details see message to the Chemicals Act of 24 November 1999 <https://www.admin.ch/opc/de/federal-gazette/2000/687 .pdf $>$ accessed 14 May 2019.

2 Federal Act on Protection against Dangerous Substances and Preparations (Chemical Act, ChemA) of 15 December 2000, SR 813.1.

3 For details on the delegated acts see Dag Kappes and Olivier Depallens, 'Swiss Chemicals Legislation: An Overview' [2018] ICRL 64.

4 Ordinance on the Placing on the Market and Handling of Biocidal Products (Ordinance on Biocidal Products, OBP, SR 813.12) 
both with and without an agreement with the EU. At the time of drafting the OBP, it was not clear whether negotiations would take place and whether they would be successful. The OBP should serve as the basis for any negotiations with the EU and had to be 'technically equivalent' to the Biocidal Products Directive of the EC (BPD). ${ }^{5}$ Since all EU Member States had to implement the directive, Switzerland could also transpose it into national law. Where the BPD assigned competences to the European Commission or EU bodies, like the Standing Committee, the OBP had provided mechanisms to take over the results of these decisions.

This is paramount for the lists of active substances: An entry of the active substances on the lists is a prerequisite for the authorisation of a biocidal product in the EU, so the lists also form the basis for an agreement in this area. Switzerland as a small country is not in a position to assess about 750 active substance / product-type combinations at the same level as the Member States of the EU in a reasonable time. ${ }^{6} \mathrm{En}-$ suring a similar level of protection to the EU, Switzerland must take over the lists of active substances and try to participate in the evaluation process through an agreement.

As in the EU, only biocidal products with notified active substances should initially be marketable in Switzerland. However, in Switzerland, products containing at least one notified active substance and otherwise only List I and / or IA active substances are subject to a transitional authorisation. Once all the active substances in a product have been included in Lists I or IA, the biocidal product had to be autho-

5 Directive 98/8/EC of the European Parliament and of the Council of 16 February 1998 concerning the placing of biocidal products on the market [1998] OJ L123/1.

61500 active substance / product-type combinations had been notified according to Commission Regulation (EC) No 1896/2000 of 7 September 2000 on the first phase of the programme referred to in Article 16(2) of BPD [2000] OJ L 228/6. See D Kappes, K Rasmussen, 'Prioritisation of existing biocidal active substances in the European Union' [2003] Environmental Science and Policy 521 . For about 750 of these substances dossiers have been submitted (See table 1).

7 Further details concerning the MRA are available <https://www .seco.admin.ch/seco/en/home/Aussenwirtschaftspolitik

_Wirtschaftliche_Zusammenarbeit/Wirtschaftsbeziehungen/ Technische_Handelshemmnisse/Mutual_Recognition_Agreement _MRA0/MRA_Schweiz_EU.html> accessed 14 May 2019.

8 Regulation (EU) No 528/2012 of the European Parliament and of the Council of 22 May 2012 concerning the making available on the market and use of biocidal products [2012] OJ L167/1. rised, recognised or registered in a procedure equivalent to the BPD.

\section{Extension of the Mutual Recognition Agreement to Biocidal Products 2010}

Following the entry into force of the OBP in 2005, Switzerland sought to negotiate an agreement in this area. It proposed to negotiate a new chapter on biocidal products in Annex I of the Agreement between the Swiss Confederation and the European Community on Mutual Recognition in relation to conformity assessment (MRA, SR 0.946.526.81), which has been in force since mid-2002. ${ }^{7}$ The prerequisite for the conclusion of a new chapter of the MRA is the technical equivalence of the Swiss regulations with those of the EU. The relevant elements of the BPD had been implemented in the Swiss OBP and both sides were willing to negotiate the new chapter. The BPD not only covered the mutual recognition of authorisations, but also procedures. Among other things, it introduced a conciliation procedure by the European Commission. If a recognising Member State considers that a biocidal product authorised by another Member State does not meet the conditions for authorisation, Article 4 (4-6) of the BPD provided for a conciliation procedure in which the European Commission takes a final decision. If Switzerland wanted to participate in the proceedings, it also had to submit to arbitration by the European Commission like the EU Member States. The chapter on biocidal products of the MRA described this conciliation procedure. At the same time Switzerland could attend the meetings of the Competent Authorities of the EU and thus participate in the so-called 'decision shaping' - but without the right to vote in the Standing Committee. The new chapter on biocidal products entered into force on 18.10.2010.

\section{Suspension of the Agreement in 2013}

Since 1 September 2013, the biocidal products regulation (BPR) applies in the EU. ${ }^{8}$ The BPD was repealed at the same time. From this moment, the Swiss OBP was no longer equivalent to the BPR. Therefore, the European Commission suspended the implementation of the chapter on biocidal products of the MRA until the Swiss legislation was technically equivalent 
Table 1: Implementation of the lists of active substances into the Swiss legislation under the BPD

\begin{tabular}{|c|c|c|c|}
\hline List of substance & $\mathrm{BPD}$ & OPB & Remarks \\
\hline $\begin{array}{l}\text { active substances with requirements agreed at } \\
\text { community level for inclusion in biocidal prod- } \\
\text { ucts }\end{array}$ & Annex I & Annex 1 & \multirow{3}{*}{$\begin{array}{l}\text { The annexes of the OPB had } \\
\text { to be adapted according to } \\
\text { the development in the EU. } \\
\text { The special provisions for the } \\
\text { inclusion of active substances } \\
\text { have been adapted to Swiss } \\
\text { terminology }\end{array}$} \\
\hline $\begin{array}{l}\text { active substances with requirements agreed at } \\
\text { community level for inclusion in low-risk bioci- } \\
\text { dal products }\end{array}$ & Annex IA & Annex 2 & \\
\hline $\begin{array}{l}\text { basic substances with requirements agreed at } \\
\text { community level }\end{array}$ & Annex IB & Annex 3 & \\
\hline $\begin{array}{l}\text { Notified, existing active substances in the 10-year } \\
\text { work programme }\end{array}$ & $\begin{array}{l}\text { Commission Regula- } \\
\text { tion (EC) No } \\
\text { 2032/2003--fnref:1-- }\end{array}$ & $\begin{array}{l}\text { Reference to } \\
\text { Regulation (EC) } \\
\text { No } 2032 / 2003\end{array}$ & $\begin{array}{l}\text { The reference was regularly } \\
\text { updated in the OPB. }\end{array}$ \\
\hline
\end{tabular}

to the BPR, which was the basis for renegotiations of the chapter on biocidal products.

\section{The Current Swiss Ordinance on Biocidal Product, Harmonised with the BPR}

With the publication of the BPR, the Swiss federal offices started the adaptation of the OBP. The revised OBP entered into force in July 2014.

\section{Challenges in Adapting the OPB to the BPR}

The BPR is 'binding in its entirety and directly applicable in all Member States' (Article 97). Only a few elements, such as compliance with the provisions of Article 65 BPR, had to be transposed into the national law of the Member States. The new elements, eg the Union authorisations and the coordinating function of ECHA had to be implemented into Swiss legislation in such a way that it can be carried out both with and without the MRA. Article $1 b$ OBP titled 'changes to this Ordinance and priority of international treaties' takes account of this fact by giving priority to an international treaty over the Swiss regulation. This was necessary because in the OBP certain procedural regulations, which apply due to the MRA, could not be introduced. Article 5 (3) of the OBP stipulates 'only persons domiciled in Switzerland or with a registered office or branch in Switzerland may apply for and hold an authorisation. This is without prejudice to the provisions of an international treaty.' With the renewal of the chapter on biocidal products of the MRA, authorisation holders from EU Member States (and also from the EEA-EFTA States, as the MRA applies also to them ${ }^{9}$ ) do not require a registered office or address in Switzerland (see also Article $11 b$ (1) of the Administrative Procedure Act, SR 172.021). Nor are the authorisation holders for a recognition obliged to indicate on the label of biocidal products an authorisation holder or a responsible person in Switzerland. Finally, the functions of the European Chemicals Agency (ECHA) could not be introduced into the OBP or were projected to the Swiss Notification Authority for Chemicals respectively. ${ }^{10}$

The BPR has defined some terms that were named differently in Swiss law, in particular in the ChemA,

9 See the Joint Declaration of the EFTA States < https://www.efta.int/ media/documents/legal-texts/efta-convention/joint-declarations/ Declaration-TBT-MRA.pdf > accessed 14 May 2019.

10 The Notification Authority for chemicals is the common authority for the notification and authorisation of chemicals of the Federal Office for the Environment (FOEN), the Federal Office of Public Health (FOPH) and the State Secretariat for Economic Affairs (SECO). 
since they were based on the EU directives valid in 2000. For example 'preparation' (Article 4 (1) (c) ChemA) is used instead of 'mixture' (EU-CLP-Regulation ${ }^{11}$ ) or 'placing on the market' (Article 4 (1) (i) ChemA) corresponds to 'making available on the market' (Article 3 (1) (i) BPR). General references of the BPR to other legal acts of the EU, which are not covered by an agreement Switzerland - EU, must be implemented in the OBP in such a way that it is clear, which legal act in which version is applicable in Switzerland. Therefore, Annex 3 OBP (Correspondence of expressions and applicable law) includes tables of correspondence between the terms of Swiss law and the ones of the BPR. In addition, either it specifies the binding versions of the EU regulations or the corresponding Swiss regulations for legal acts referred to by the BPR.

\section{The Problem of Free Riding - Implementation of Article 95 BPR into the OBP}

The implementation of Article 95 BPR, which regulates the transitional measures for access to the dossiers of the active substances, was particularly difficult. This Article is intended solely to protect the economic interests of holders of the active substance dossiers against free riders. Health and environmental protection are for once not in focus here. The owners of the dossiers already invested money and resources in the generation of data and the dossier years ago. However, as long as the active substance had not been included into the Union list or in Annex I BPR, they did not benefit at all. This changed with effect from 1 September 2015. Since then only biocidal products may be made available on the market if the active substance and

11 Regulation (EC) No 1272/2008 of the European Parliament and of the Council of 16 December 2008 on classification, labelling and packaging of substances and mixtures, amending and repealing Directives 67/548/EEC and 1999/45/EC and amending Regulation (EC) No 1907/2006 [2008] OJ L353/1.

12 ECHA, 'Information on biocides' <https://echa.europa.eu/ information-on-chemicals/active-substance-suppliers $>$ accessed 14 May 2019.

13 The homepage of the Notification Authority shows an overview $<$ https://www.anmeldestelle.admin.ch/chem/en/home/themen/ pflicht-hersteller/zulassung-biozidprodukte.html > accessed 14 May 2019 the supplier is listed in ECHA's Article 95 list of active substances and suppliers. ${ }^{12}$ As Switzerland takes over the lists of active substances from the EU, the holders of transitional authorisations had to submit a confirmation that their active substance supplier of the notified active substance is registered on the ECHA Article 95 list (Article 62d OBP). For new applications, this proof is part of the dossier (Annex $8 \mathrm{OPB}$ ). If the supplier is not listed, it is possible for the holder of the authorisation to change the supplier or to register himself on the list. The latter option requires a letter of access to the dossier of the active substance. These requirements are intended to ensure the financial participation of all economic operators making available biocidal products on the market. The aim is to stop the previously possible free riding in Switzerland, too.

\section{Authorisation Procedures According to OBP}

The OBP defines a number of procedures for placing biocidal products on the market. The main types are summarised in table 2.

The type of procedure depends on the status of the active substances and whether and how the product is already authorised in a Member State. ${ }^{13}$

a. Procedures Harmonised with the BPR Covered by the MRA

- Authorisation $A_{L}$ based on a comprehensive assessment of the biocidal product: For biocidal products containing at least one active substance in the Union list and which, moreover, contain only active substances listed in Annex 1 OPB. Alternatively, they may contain only active substances listed in Annex 1 OPB. In total, 12 applications were submitted by May 2019 (including three requests for the evaluation of Union authorisations), five products have been authorised and one refused.

- The simplified authorisation: For biocidal products which are suitable for the simplified process in accordance with Article 25 of the BPR. By May 2019, the Notification Authority has not yet received any application. 
Table 2: Main authorisation types in Switzerland

\begin{tabular}{|c|c|c|c|c|}
\hline & Authorisation type & \multicolumn{3}{|c|}{ Requirements for the active substances } \\
\hline & & notified & Annex 1 OPB & Annex 2 OPB \\
\hline $\mathrm{A}_{\mathrm{L}}$ & $\begin{array}{l}\text { Authorisation under the harmonised pro- } \\
\text { cedure }\end{array}$ & & $(\mathrm{x})$ & $\mathrm{x}$ \\
\hline $\begin{array}{l}\text { Simplified authorisa- } \\
\text { tion }\end{array}$ & $\begin{array}{l}\text { Simplified authorisation under the har- } \\
\text { monised procedure }\end{array}$ & & $\mathrm{x}$ & \\
\hline Recognition & $\begin{array}{l}\text { Recognition of an authorisation of an } \\
\text { EEA Member State }\end{array}$ & & $(\mathrm{x})$ & $\mathrm{x}$ \\
\hline $\begin{array}{l}\text { Recognition of a } \\
\text { Union Authorisation }\end{array}$ & $\begin{array}{l}\text { Automatic recognition of a Union Autho- } \\
\text { risation }\end{array}$ & & $(\mathrm{x})$ & $\mathrm{x}$ \\
\hline $\begin{array}{l}\text { Authorisation of the } \\
\text { same biocidal prod- } \\
\text { ucts }\end{array}$ & $\begin{array}{l}\text { same biocidal products: being identical to } \\
\text { already authorised biocidal products }\end{array}$ & \multicolumn{3}{|c|}{ Like in the reference product } \\
\hline$A_{N} / A_{C}$ & Transitional authorisation & $\mathrm{x}$ & $(\mathrm{x})$ & $(\mathrm{x})$ \\
\hline
\end{tabular}

- Mutual recognition in parallel or in sequence of a national authorisation already granted in an EEA Member State: In total, the Notification Authority has authorised more than 300 applications (including biocidal products families) by May 2019.

- Recognition of a Union authorisation: for biocidal products for which the European Commission has granted a Union authorisation. The Swiss authorities decide on the admission of a Union authorisation in accordance with Article $14 a$ OBP. ${ }^{14}$ Under the MRA, the submission of the Union authorisation to ECHA is considered as submission to the Swiss Notification Authority. The Swiss Authorities already have knowledge of the dossier due to their participation in the Peer review of the PAR and in the ECHA-Biocidal Products Committee. The recognition of a Union authorisation is granted in Switzerland within 30 days and is free of charge (article 57 (2) OBP).

- Authorisation of same biocidal products: For biocidal products, being identical to already authorised biocidal products and placed on the market by the authorisation holder or by third parties under the same conditions as the biocidal products already authorised. By May 2019, the Notification
Authority has received about 50 applications for same biocidal products.

- Authorisation for parallel trade (Article 53 BPR): for biocidal products authorised according to the harmonised procedure in an EEA Member State being identical to a biocidal product authorised in Switzerland. No application has been received in Switzerland until Mai 2019.

- Notification procedures: Notifications are necessary for simplified authorised biocidal products from the EEA and for products of an authorised biocidal product family.

b. National Procedures not Covered by the MRA

- Transitional authorisation for Biocidal Products containing at least one notified active substance and otherwise only active substances listed on the Union list of authorised active substances (list of

14 For details see <https://www.anmeldestelle.admin.ch/chem/en/ home/themen/pflicht-hersteller/zulassung-biozidprodukte/ zulassung-europaeisch-verfahren/unionszulassung.html>accessed 14 May 2019. 
active substances approved in accordance with Article 9 of the BPR) or Annex I BPR (list of active substances referred to in Article 25(a) - simplified procedure). The supplier of the notified active substances must be listed on the ECHA Article 95 list. In total, 4000 products have been authorised in Switzerland under this transitional scheme (authorisation $A_{N}$ ) by May 2019. In addition, the Notification Authority has confirmed 935 authorisations $\left(A_{C}\right)$ for biocidal products that had been on the market before the chemicals law was in force. The numbers of these authorisations will decrease in the next years as the list of notified active substances becomes shorter and shorter as more existing active ingredients are evaluated.

- Authorisation to deal with exceptional situations.

- Authorisation $A_{n L}$ based on a comprehensive assessment of the biocidal product and its active substances: For biocidal products, containing at least one active substance not included in any of the lists mentioned above. The authorisation $\mathrm{A}_{\mathrm{nL}}$ represents the possibility of how an applicant can place a product on the market in Switzerland with an active substance that is not listed. It is intended for the non-MRA scenario and has been retained in case the MRA would be suspended again. This type of authorisation requires a comprehensive dossier and a (cost-)intensive evaluation of the active substance. Products authorised under this procedure can only be placed on the market in Switzerland. A recognition by EEAMember States is not foreseen. Therefore, this authorisation type has not yet gained any practical significance. Since the entry into force of the OBP in 2005, the Notification Authority has not re-

15 Biozidprodukte-Vollzugsverordnung EDI; SR 813.121; available in German, French or Italian.

16 Commission Implementing Regulation (EU) No 414/2013 of 6 May 2013 specifying a procedure for the authorisation of same biocidal products in accordance with Regulation (EU) No $528 / 2012$ of the European Parliament and of the Council, OJ L 125 of 7.5.2013, 4; last amended by Regulation (EU) No 2016/1802 [2016] OJ L275/27.

17 Commission Implementing Regulation (EU) No 354/2013 of 18 April 2013 on changes of biocidal products authorised in accordance with Regulation (EU) No 528/2012 of the European Parliament and of the Council [2013] OJ L109/4.

18 For a list of Art 3(3) BPR Commission decisions see <https://echa .europa.eu/de/regulations/biocidal-products-regulation/legislation $>$ accessed 14 May 2019. ceived any application for this type of authorisation.

- Authorisation of parallel trade in biocidal products being placed on the market in EEA Member States and in Switzerland in accordance with the national transitional provisions. This provision should prevent that an exclusive representative or general importer can exclusively place on the Swiss market a biocidal product at an increased price. The proposed scheme favours competition and aims to reduce the price of biocidal products. The Notification Authority received only few applications, but did not authorise any of them.

\section{The Biocidal Product Implementing Ordinance ${ }^{15}$}

In order to adapt the BPR to the technical progress and to harmonise the enforcement between EU Member States, the European Commission can adopt implementing regulations and delegated acts based on delegation standards in the BPR. Also in Switzerland, the Federal Council delegated this competence. The Federal Department of Home Affairs in agreement with the Federal Department of the Environment, Transport, Energy and Communications and the Department of Economic Affairs, Education and Research, is empowered in various Articles of the OPB to introduce detailed provisions. The Biocidal Products Implementing Ordinance transposes two Commission Implementing Regulations concerning procedure for the authorisation of same biocidal products $^{16}$, and changes of biocidal products authorised in accordance with the BPR. ${ }^{17}$

Based on article 3 (3) BPR the European Commission may, at the request of a Member State, decide, by means of implementing acts, whether a substance is a nanomaterial, and whether a specific product or group of products is a biocidal product or a treated Article or neither. For example, the decision on a horse rug impregnated with permethrin used for controlling nuisance insects in the environment of the horse, which shall be considered as a biocidal product. ${ }^{18}$ These implementing decisions, which serve the interpretation of the BPR, are not implemented in Swiss law. However, Article 50 a OBP aims to achieve harmonisation in enforcement. Therefore, the Swiss authorities shall be guided by the legislation currently applicable in the EU, and in particular by delegat- 
ed acts or implementing acts adopted by the European Commission in accordance with the BPR and by Technical Notes for Guidance issued by the European Commission or the ECHA.

Judges of Swiss courts will take into account these Commission implementing decisions in the decisionmaking process. Switzerland also may request the European Commission for such an implementation decision as to whether a specific product or product group is a biocidal product, a treated Article or neither.

\section{The Revised Chapter on Biocidal Products of the MRA}

The technical equivalence of the OBP to the BPR enabled a revision of the chapter on biocidal products of the MRA. It entered into force on 14 April 2015. ${ }^{19}$ The structure of the chapter is as follows.

\section{Scope and Coverage}

The provisions apply to active substances, biocidal products, biocidal product families, and treated Articles, as defined in article 3 of the BPR.

Exempted from the mutual recognition are:

- Biocidal products which are or which contain genetically modified microorganisms. This exception is inter alia necessary, because these products are not only authorised in Switzerland according to the OBP but also have to fulfil the requirements for the handling of genetically modified organisms and, if necessary, licensing, reporting and notification requirements of the Release Ordinance (RO). ${ }^{20}$

- Avicides, piscicides and biocides for control of other vertebrates. Biocidal products of these product types are not to be authorised in Switzerland in accordance with Article 4 (1) OBP. For each of these product types (15, 17 and 20), each Member State may in any case refuse to grant authorisations for animal welfare reasons under Article 37 (4) of the BPR.

- Swiss restrictions, which are more severe than in the EU.The MRA grants Switzerland the right to continue to apply two prohibitions under the Chemical Risk Reduction Ordinance (ORRChem) to biocidal products, namely: ${ }^{21}$

- biocidal products containing octylphenol or its ethoxylates (Annexe 1,8 ORRChem), and

- Aerosol dispensers containing substances stable in the air (Annexe 1.5 ORRChem). The most prominent example of an air-stable substance is the propellant R134a, forbidden in Switzerland but not in the EU.

\section{Legislative, Regulatory and Administrative Provisions}

This section lists the legal bases in the EU (BPR) and in Switzerland (ChemA, the Environmental Protection Act $(\mathrm{EPA})^{22}$, the OPB and the Biocidal Product Implementing Ordinance).

\section{Conformity Assessment Bodies}

This section specifies the ECHA as well as the national competent authorities for the EU and the Notification Authority for Switzerland as conformity assessment bodies.

\section{Supplementary Provisions}

\section{a. Amendments to Legislative, Regulatory and Administrative Provisions of Section I}

The biocidal products chapter provides for a constant adaptation of the Swiss legislation to the technical progress of the EU acquis. To this end, the EU notifies implementing and delegated acts to the Swiss authorities, which then implements it and then notifies the EU in turn.

19 Decision No 1/2015 of the Committee established under the Agreement between the European Community and the Swiss Confederation on mutual recognition in relation to conformity assessment of 14 April 2015 on the amendment of Chapter 16 on construction products, Chapter 18 on biocidal products and the update of legal references listed in Annex 1 [2015/1058] [2015] OJ $L 171 / 25$. 
b. Procedures of the BPR and its Implementing Acts that Apply between the Parties

It states that an authorisation holder and the person referred to in Article 95 of the BPR may be established in the EU or in Switzerland.

Applicants shall use the Register for Biocidal Products to submit applications and data for all procedures as foreseen in Article 71(3) of the BPR.

In addition to the harmonised authorisations covered by the MRA as described above (III. 3. a.) The following Articles of the BPR are considered common:

- Articles 35-37 on objections and derogations.

- Articles 47-50 and Commission Implementing Regulation (EU) No 354/2013 as regards the notification of adverse effects and rules on cancellation or amendments.

- Article 54 as regards the establishment of technical equivalence of active substances.

- Articles 62-63 on data sharing. An applicant submitting a request to the Swiss competent authority shall be re-directed to the Agency and enter its request into the Register ( $\left.\mathrm{R}_{4} \mathrm{BP}\right)$.

- Article 69 (2) as regards the name and address of the authorisation holder and the authorisation number to be provided on labels.

- Article 88 as regards measures taken on the basis of new evidence.

- Article 95

- The procedure if Switzerland intends to deviate from a decision of the EU.

23 ECHA, 'The way we work' < https://echa.europa.eu/about-us/the -way-we-work/financial-management-and-budgetary-reporting/ 2019> accessed 14 May 2019.

24 Commission Delegated Regulation (EU) 2019/157 of 6 November 2018 amending Annex II to Delegated Regulation (EU) No $1062 / 2014$ on the work programme for the systematic examination of all existing active substances contained in biocidal products referred to in Regulation (EU) No 528/2012 of the European Parliament and of the Council [2019] OJ L31/1.

25 Commission Delegated Regulation (EU) 2019/227 of 28 November 2018 amending Delegated Regulation (EU) No 1062/2014 as regards certain active substances/product-type combinations for which the competent authority of the United Kingdom has been designated as the evaluating competent authority [2019] OJ L37/1.

26 See 43 of the booklet of the Directorate for European Affairs, Switzerland and the European Union ( $2^{\text {nd }}$ revised edition, Bern 2016) <https://www.eda.admin.ch/content/dam/eda/en/ documents/publications/EuropaeischeAngelegenheiten/Schweiz -und-EU_en.pdf> accessed 14 May 2019.

\section{c. Information Exchange}

The subsection regulates the exchange of information between the contracting parties as well as data protection.

\section{d. Financial Contribution for Services Provided by the ECHA}

Finally, the biocidal products chapter foresees an annual financial contribution of Switzerland for services provided by ECHA. The contribution is calculated from ECHA's biocidal product costs (not covered by fees) in accordance with the Gross Domestic Product (GPD) of Switzerland divided by the GPD of all participating States. This amount varies from year to year, but is in the order of $€ 200,000$; in 2018 , it was about $€ 180,000 .^{23}$

Switzerland may be designated as evaluating Competent Authority. Commission Delegated Regulations (EU) 2019/157 and (EU) 2019/227 attribute two active substances to Switzerland for evaluation. $^{24,25}$

The ECHA and the EU Commission invite Swiss authorities to the meetings of the biocidal bodies of ECHA and the EU. Switzerland can actively participate in the decision shaping process, but has not the right to vote in the Standing Committee on Biocidal Products, like the EEA-EFTA States (Norway, Iceland and Liechtenstein).

\section{Challenges}

\section{Institutional Issues}

At the political level, the EU is asking for a solution of the so-called institutional issues for the bilateral agreements in order to ensure a more uniform and efficient application of existing and future market access agreements. The crucial points are:

- bringing the agreements in line with developments in EU law,

- interpreting the agreements,

- monitoring the agreements and

- settling disputes in terms of agreements. ${ }^{26}$

In the years 2014-2018, Switzerland and the EU have been negotiating an agreement on these institutional issues. The foreseen roadmap is delayed, as 
the Federal Council decided in December 2018 to launch a broad consultation on the negotiated text. ${ }^{27}$

\section{Continuous Adaptation to Technical Progress}

Switzerland must regularly adapt its lists of active substances (Annexes 1 and 2 OBP) to Annex I BPR and the Union list of approved active substances. The Federal Council empowered the Federal Office of Public Health to adapt these lists in a short procedure without consultation of the interested parties. Since March 2018, the lists are published electronically on internet. ${ }^{28}$ The federal offices are discussing, how to update the lists in a more efficient way.

Switzerland is implementing the Commission Implementing Regulations and Delegated Acts of the European Commission - as far as necessary -by changing the ordinances after consultation of the interested parties.

\section{The Effects of the MRA}

The inclusion of biocidal products in the MRA ensures a very high level of protection for man and the environment in Switzerland through the two-stage process of evaluation and approval of the active substances and the assessment and authorisation of the products. The EEA-Member States and Switzerland are sharing the burden of the evaluation of the active substances and the biocidal products. However, the high costs of dossiers preparation or of the letter of access and the elevated fees are a particular deterrent to small and medium-sized enterprises (SMEs). ${ }^{29}$

Switzerland takes part in the harmonised system of biocidal products authorisation. Once all the active substances of a biocidal product have been included either in the Union list or in Annex I BPR, the biocidal product has to comply with the provisions of the BPR. Switzerland cannot facilitate the placing on the market of niche products or of products that are marketed in small quantities only. On the part of the Swiss authorities, the MRA requires additional human resources through active participation in the meetings of the biocidal bodies of ECHA and the EU. However, this will generate knowledge about the methodology of assessing chemicals that Switzerland otherwise could not easily access to.

Overall, Switzerland benefits from the MRA.

From the point of view of the EU, another state shares the financial burdens and participates in the different evaluation procedures. This is especially important as the United Kingdom is leaving the EU.

27 More information and the negotiated text is online $<$ https://www .eda.admin.ch/dea/en/home/verhandlungen-offene-themen/ verhandlungen/institutionelles-abkommen.html > accessed 14 May 2019.

28 Federal Council, 'Biocidal active substances' $<$ https://www .anmeldestelle.admin.ch/chem/en/home/themen/pflicht-hersteller/ zulassung-biozidprodukte/biozide-wirkstoffe.html> accessed 14 May 2019.

29 The fees in Switzerland are in line with those of their neighbouring states; cf. Annex 2 of the Chemicals Fees Ordinance (ChemGebV; SR 813.153.1); available in German, French and Italian. 